\title{
Opposing Regulation of Pair Bond Formation by cAMP Signaling within the Nucleus Accumbens Shell
}

\author{
Brandon J. Aragona and Zuoxin Wang \\ Department of Psychology and Program in Neuroscience, Florida State University, Tallahassee, Florida 32306-1270
}

The formation of monogamous pair bonds, by prairie voles, is facilitated by activation of dopamine (DA) $\mathrm{D}_{2}$-like, but not $\mathrm{D}_{1}$-like, receptors within the nucleus accumbens (NAcc) shell. Because DA exerts opposing regulation of cAMP production depending on the subtype of receptor activated, we tested the hypothesis that DA regulation of pair bond formation is mediated via the cAMP signaling cascade. Consistent with activation of $\mathrm{D}_{2}$-like receptors, decreasing cAMP signaling, by blocking cAMP binding sites on protein kinase $\mathrm{A}$ (PKA), facilitated partner preference formation. Conversely, increasing cAMP signaling, by preventing the activation of inhibitory G-proteins, activating stimulatory G-proteins, or stimulating PKA prevented the formation of mating-induced partner preferences. These manipulations were effective in the shell, but not the core, of the NAcc. Together, these data demonstrate opposing regulation over pair bond formation by cAMP signaling within the NAcc shell.

Key words: dopamine; cAMP; G-protein; Nacc; PKA; voles

\section{Introduction}

Prairie voles (Microtus ochrogaster) are a monogamous species of rodent in which mates form life-long pair bonds (Dewsbury, 1987; Carter and Getz, 1993). In addition to being an ideal model for studies of social attachment (Wang and Aragona, 2004; Young and Wang, 2004), the naturally occurring association between pair bonded mates provides an ethologically sound model for investigating the neurobiology of adaptive learning (Aragona et al., 2003; Insel, 2003). Among the brain regions important for this process is the nucleus accumbens (NAcc), as it is critical for learning related to motivation (Di Chiara et al., 2004; Kelley, 2004; Wise, 2004; Everitt and Robbins, 2005; Nestler, 2005). Because a great deal of motivated behavior is centered around social interactions (e.g., finding mates and rearing offspring), it is not surprising that the NAcc is essential for social attachment (Keer and Stern, 1999; Stern and Lonstein, 2001; Champagne et al., 2004; Numan et al., 2005), including monogamous pair bonding (Gingrich et al., 2000; Liu and Wang, 2003; Aragona et al., 2006).

Within the NAcc, pair bond formation is mediated by highly specific dopamine (DA) transmission. The strong mate preference formed by prairie voles is facilitated by activation of $\mathrm{D}_{2}$-like receptors within the rostral shell of the NAcc, whereas activation of $\mathrm{D}_{1}$-like receptors prevents this behavior (Aragona et al., 2006). Although similar regulation has been shown for reinstatement of drug seeking (Self et al., 1996), the opposite has been found for the motivation to seek drug (Lynch and Taylor, 2005) and for

Received July 16, 2007; revised 0ct. 24, 2007; accepted 0ct. 24, 2007.

This work was supported by National Institutes of Health Grants MH-67396 (B.J.A.) and MHR01-58616, DAR0119627, and DAK02-23048 (Z.X.W.). We thank Dr. Yan Liu for her expert assistance and Bobby Wheels, Joshua J. Jones, and Jeremy H. Day for critical reading of this manuscript.

Correspondence should be addressed to Dr. Zuoxin Wang, Department of Psychology, Florida State University, Tallahassee, FL 32306-1270. E-mail: zwang@neuro.fsu.edu.

DOI:10.1523/JNEUROSCI.3216-07.2007

Copyright $\odot 2007$ Society for Neuroscience $\quad$ 0270-6474/07/2713352-05\$15.00/0 food seeking behavior (Eyny and Horvitz, 2003). Moreover, activation of both receptor subtypes is required for site directed self-administration of DA agonists (Ikemoto et al., 1997). Given such disparate findings, the nature of DA receptor regulation of motivated behavior is controversial. Therefore, the goal of the present study was to determine a mechanism by which NAcc DA can have the receptor-specific regulation shown previously to mediate pair bond formation (Aragona et al., 2006).

Opposing behavioral regulation by $\mathrm{D}_{1}$ - and $\mathrm{D}_{2}$-like $\mathrm{DA}$ receptors is expected, because their categorization is based on opposing regulation over intracellular signaling (Missale et al., 1998). $\mathrm{D}_{2}$-like receptors are bound to inhibitory G-proteins, which decrease the production of cAMP (Missale et al., 1998; Neve et al., 2004). Conversely, $D_{1}$-like receptors are coupled with stimulatory G-proteins, and activation of these receptors increases cAMP production, which acts primarily through binding protein kinase A (PKA) (Missale et al., 1998; Neve et al., 2004). Given that DA exerts opposing regulation over cAMP signaling, we hypothesized that this system is responsible for the opposing dopaminergic regulation over pair bond formation (Aragona et al., 2006). Because $\mathrm{D}_{2}$-like receptor activation promotes pair bonding (Gingrich et al., 2000; Liu and Wang, 2003; Aragona et al., 2006), we first tested whether decreased cAMP signaling, within both the NAcc core and shell, facilitates pair bond formation. Then, because $\mathrm{D}_{1}$-like activation antagonizes pair bonding (Aragona et al., 2006), we tested whether increased cAMP signaling prevents pair bond formation.

\section{Materials and Methods}

Subjects. Subjects were sexually naive male prairie voles from a laboratory breeding colony described in detail previously (Aragona et al., 2003; Liu and Wang, 2003). Ovariectomized females served as stimulus animals. Subjects were assigned into either the $6 \mathrm{~h}$ cohabitation or $24 \mathrm{~h}$ mating group, followed by a partner preference test (see below). For manipulations that required mating ( $24 \mathrm{~h}$ mating), females were estrogen primed 


\section{A- 6 h cohabitation}

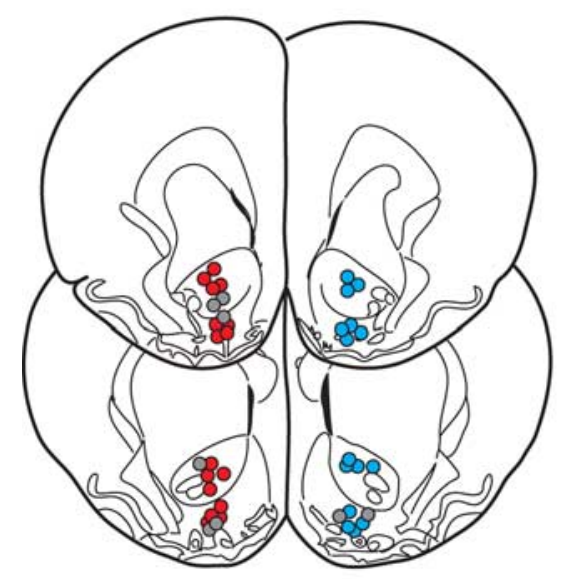

B- $24 \mathrm{~h}$ with mating

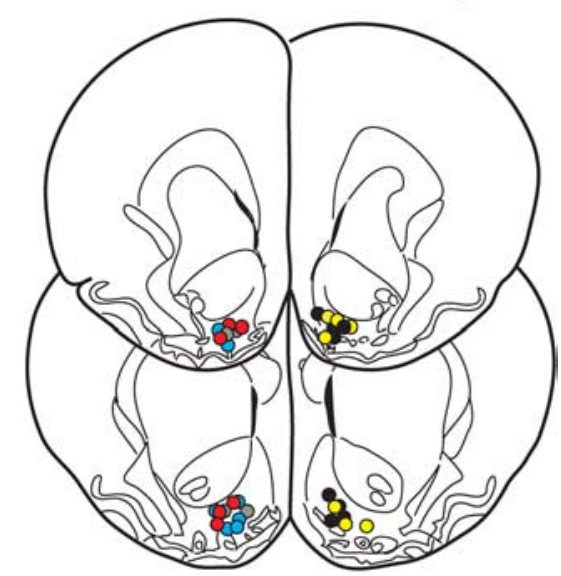

$$
\mathrm{CSF}=0 \quad \mathrm{Rp}=0 \quad \mathrm{Sp}=0 \quad \mathrm{PTX}=0 \quad \mathrm{CTX}=
$$

Figure 1. Locations of site-specific drug infusions. $\boldsymbol{a}$, Infusions for drug induced facilitation of partner preferences into either the NAcc shell or core. $\boldsymbol{b}$, Infusions for pharmacological blockade of mating-induced partner preferences focused on the NAcc shell.

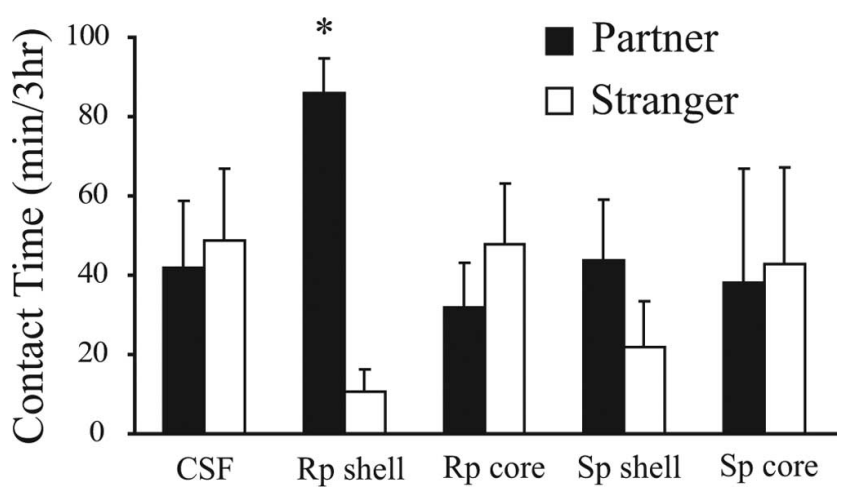

Figure 2. Decreased PKA activity within the NAcc shell, but not core, facilitates partner preferences. Infusions of CSF $(n=8)$ resulted in nonselective side-by-side contact between partners and strangers. Intra-shell $(n=8)$, but not core $(n=8)$ administration of Rp ( $8 \mathrm{ng})$ induced a significant partner preference. Activation of PKA with Sp $(8 \mathrm{ng})$ did not induce partner preferences when infused in either the shell $(n=8)$ or the core $(n=7) .{ }^{*} p<0.05$, significantly more time with the partners compared with strangers. Error bars indicate SEM.

with subcutaneous estrodial benzoate pellets implanted $4 \mathrm{~d}$ before pairing. All behavioral interactions during $6 \mathrm{~h}$ cohabitation and $24 \mathrm{~h}$ mating were videotaped for detailed behavioral analysis.

Stereotaxic cannulation and microinfusion. Subjects were anesthetized with sodium pentobarbital ( $2.5 \mathrm{mg}$ per $40 \mathrm{~g}$ body weight), and 26 gauge bilateral guide cannulas (Plastics One, Roanoke, VA) aimed at NAcc were implanted stereotaxically [nose bar $-2.5 \mathrm{~mm} ; 1.6 \mathrm{~mm}$ rostral, $\pm 1 \mathrm{~mm}$ bilateral, $4.5 \mathrm{~mm}$ ventral (for shell), $3.5 \mathrm{~mm}$ ventral (for core) to bregma]. After 3-5 d recovery, subjects received microinfusions (200 $\mathrm{nl} /$ side) of either CSF or CSF containing pertussis toxin (PTX), cholera toxin (CTX), Rp-cAMPS (Rp), or Sp-cAMPS (Sp). It is important to note that these compounds influence additional signaling mechanisms beyond those emphasized in the present study (Yip, 2006). Drugs were always mixed fresh before administration and dosage was based on previous literature (Self et al., 1998) as well as pilot tests on general locomotor activity. Microinfusions through a 33 gauge needle were made at a rate of $200 \mathrm{nl} / \mathrm{min}$ (model 210; KD Scientific, Holliston, MA) for $1 \mathrm{~min}$.

Partner preference test. Pair bond formation is assessed by a threechambered apparatus, described in detail previously (Aragona et al., 2003; Liu and Wang, 2003), which allows subjects to choose between the familiar "partner" and unfamiliar "stranger." Activity is recorded by motion sensors and social contact is scored by experimenters blind to treatment. Partner preferences were analyzed with a paired samples $t$ test, and group differences in the frequency of total cage entries were analyzed using a one-way ANOVA. The number of cage crossings and frequency and duration of social contact during the $6 \mathrm{~h}$ cohabitation as well as mating bouts, frequency and duration of social contact during the $24 \mathrm{~h}$ mating were also recorded and compared between treatment groups with a one-way ANOVA followed by a Student-Newman-Keuls post hoc test.

\section{Results}

Decreased cAMP signaling within the NAcc shell induces partner preference formation

Pair bond formation is studied in the laboratory by a "partner preference" test (Williams et al., 1992), in which subjects are free to cohabitate with their familiar partner (housed with the subject before the partner preference test) or an unfamiliar stranger (had not previously encountered the subject). A partner preference is defined by subjects spending significantly more time in side-by-side contact with their partners compared with strangers. For male prairie voles, $6 \mathrm{~h}$ of nonsexual cohabitation with a female does not produce a partner preference (Winslow et al., 1993; Aragona et al., 2003; Liu and Wang, 2003), but administration of a $\mathrm{D}_{2}$-like agonist within the NAcc shell induces this behavior (Aragona et al., 2006). Therefore, this paradigm was used to test whether decreasing cAMP signaling would induce partner preferences.

Because cAMP signaling is primarily mediated through binding PKA, manipulating CAMP binding sites on PKA is a widely accepted method to study cAMP transmission (Self et al., 1998; Baldwin et al., 2002; Beninger and Gerdjikov, 2004; Lynch and Taylor, 2005). The typical "cAMP antagonist," Rp-cyclic adenosine 3',5' -phosphorothioate (Rp), is a competitive inhibitor for cAMP binding sites on PKA which maintains PKA in its inactive state (Schwede et al., 2000). The typical cAMP agonist is the corresponding isomer, Sp-cyclic adenosine $3^{\prime}, 5^{\prime}$-phosphorothioate (Sp), which maintains PKA in its active state (Schwede et al., 2000). Each drug was infused into either the shell or core subregion of the NAcc (Fig. 1a). These subregions mediate different aspects of motivated learning, with the shell implicated in primary reinforcement and the core in conditioned reinforcement (Di Chiara et al., 2004; Kelley, 2004; Everitt and Robbins, 2005). After site-directed infusions of vehicle or drug, subjects were paired with a female for $6 \mathrm{~h}$ of cohabitation in the absence of mating, and thereafter, tested for partner preferences.

As expected, control subjects that received CSF infusions within the NAcc (core or shell; $n=8$ ) before 6 h of cohabitation failed to show a partner preference (i.e., they displayed nonselective side-by-side contact during the partner preference test) (Fig. $2)$. However, reduction in cAMP signaling within the NAcc shell $(8 \mathrm{ng} \mathrm{Rp} ; n=8)$ resulted in a robust partner preference $(p<$ 0.01 ) (Fig. 2). This drug produced no effect when infused into the NAcc core $(n=8)$ (Fig. 2). Increased activation of the cAMP system (by infusion of $8 \mathrm{ng} \mathrm{Sp}$ ) did not produce partner prefer- 
Table 1. Behavior during the facilitation of partner preferences

\begin{tabular}{|c|c|c|c|c|c|}
\hline & CSF & Rp shell & Rp core & Sp shell & Sp core \\
\hline \multicolumn{6}{|l|}{6 h cohabitation } \\
\hline Central cage crossing $(n)$ & $151.6 \pm 26.9^{*}$ & $142.3 \pm 32.5$ & $184.6 \pm 48.5$ & $175.1 \pm 20.0$ & $208.8 \pm 90.3$ \\
\hline Contact duration (min) & $162.6 \pm 11.2$ & $150.0 \pm 29.5$ & $113.6 \pm 25.3$ & $163.6 \pm 17.3$ & $171.0 \pm 14.2$ \\
\hline Contact frequency $(n)$ & $41.5 \pm 4.3$ & $36.3 \pm 5.6$ & $33.3 \pm 2.5$ & $33.9 \pm 3.3$ & $39.0 \pm 4.1$ \\
\hline \multicolumn{6}{|l|}{ Partner preference test } \\
\hline Cage entries $(n)$ & $99.1 \pm 23.2$ & $82.1 \pm 14.0$ & $94.5 \pm 25.9$ & $113.9 \pm 15.9$ & $124.2 \pm 30.0$ \\
\hline
\end{tabular}

*Mean \pm SEM.

ences when the drug was injected into either the shell $(n=8)$ (Fig. 2 ) or core $(n=7)$ (Fig. 2).

Drug treatment did not affect general locomotor activity, as groups did not differ in the number of center cage crosses during the $6 \mathrm{~h}$ cohabitation or the number of cage entries during the partner preference test (Table 1). In addition, drug treatment did not affect subject's social contact with the female partner during the $6 \mathrm{~h}$ cohabitation. Therefore, manipulation of partner preferences was not a secondary effect of drug induced changes in locomotor activity and/or initial social interactions, but rather, decreased cAMP signaling within the NAcc shell appears to directly mediate pair bond formation.

\section{Increased activation of the cAMP system blocks mating- induced partner preference formation}

We next tested the necessity of cAMP signaling by manipulating the naturally occurring partner preferences formed during $24 \mathrm{~h}$ of ad libitum mating (Winslow et al., 1993; Wang et al., 1999; Aragona et al., 2003). Because activation of $\mathrm{D}_{1}$-like receptors prevents partner preferences (Aragona et al., 2006), we hypothesized that increased cAMP signaling would interfere with matinginduced partner preference formation. Furthermore, as the effects on partner preferences by DA receptor manipulation (Aragona et al., 2006) and by reduced cAMP signaling (Fig. 2) are restricted to the NAcc shell, our manipulations of naturally occurring partner preferences were focused on the shell (Fig. 1b). Additionally, cAMP signaling was increased by preventing the activity of inhibitory G-proteins with PTX or by activating stimulatory G-proteins with CTX. Immediately after vehicle or drug treatment, subjects were paired with a female for $24 \mathrm{~h}$ of ad libitum mating and then tested for partner preferences.

As has been shown previously (Aragona et al., 2003; Aragona et al., 2006), subjects receiving vehicle infusions of CSF showed robust mating-induced partner preferences after 24 h of pairing $(n=4$; $p<$ 0.05 ) (Fig. 3). However, preventing the function of inhibitory G-proteins by PTX infusion ( $n=8 ; 20 \mathrm{ng}$ ) blocked mating-induced partner preferences (Fig. 3). Activating stimulatory G-proteins with intrashell infusions of CTX ( $n=8 ; 20 \mathrm{ng})$ also blocked matinginduced partner preference formation (Fig. 3). Consistent with G-protein manipulations, increasing cAMP signaling by activating PKA ( 8 ng Sp; $n=7$ ) prevented mating-induced partner preferences (Fig. 3). However, decreasing PKA activity ( $8 \mathrm{ng} \mathrm{Rp} ; n=6$ ) did not disrupt partner preferences ( $p<0.05$; Fig. 3 ).

Drug manipulations had no effect on locomotor activity during the partner preference test as indicated by the number of cage entries (Table 2). This is especially important because these drugs are still active $24 \mathrm{~h}$ after infusion (Self et al., 1994; Lynch and Taylor, 2005). Furthermore, no group differences were found in the number of mating bouts or in the duration of social contact during 24 h of pairing (Table 2). Although differences were found in contact frequency during $24 \mathrm{~h}$ of pairing (Table 2), they do not seem to contribute to the observed group differences in partner

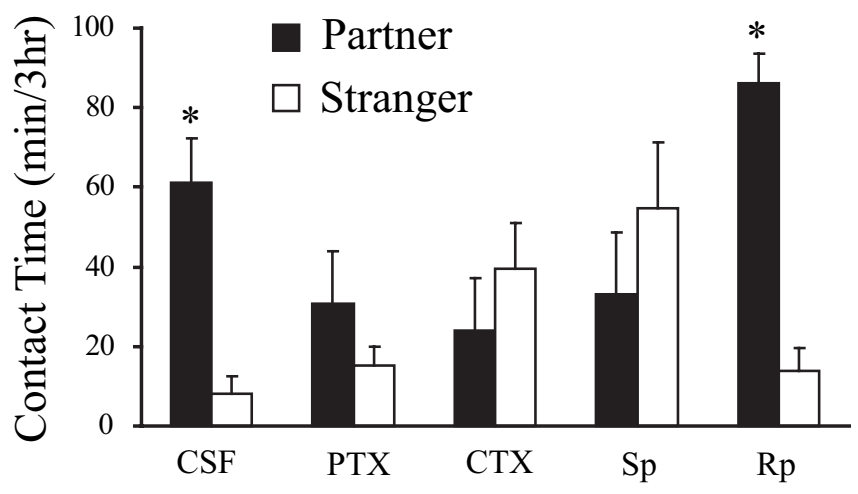

Figure 3. Increased CAMP signaling within the NAcc shell blocks mating-induced partner preferences. Subjects receiving control infusions of CSF $(n=4)$ showed robust mating-induced partner preferences. Preventing activity of inhibitory G-proteins with PTX (20 ng; $n=8)$, activating stimulatory G-proteins with CTX (20 ng; $n=8)$, and activating PKA with Sp (8 ng; $n=7$ ) prevented mating-induced partner preferences. Decreasing PKA activity with Rp (8ng; $n=6$ ) did not alter mating-induced partner preferences. ${ }^{*} p<0.05$, significantly more time with the partners compared with strangers. Error bars indicate SEM.

preference formation. Together, these data indicate that increased cAMP signaling within the NAcc shell directly interferes with pair bond formation.

\section{Discussion}

This study provides the first characterization of an intracellular mechanism regulating the formation of monogamous pair bonds. Decreasing cAMP signaling, by preventing cAMP activation of PKA, facilitated partner preferences. In contrast, increasing CAMP signaling, both by manipulations of G-proteins and PKA, prevented partner preference formation. These effects were specific to the NAcc shell, as manipulations of the NAcc core had no effect. Thus, the cAMP signaling pathway within the NAcc shell exerts opposing regulation over pair bond formation. These results are consistent with our recent findings showing that activation of $\mathrm{D}_{2}$-like DA receptors facilitates, whereas $D_{1}$-like receptors prevents, partner preference formation (Aragona et al., 2006). Together, these data support the hypothesis that opposing dopaminergic regulation over pair bond formation is mediated via the cAMP system.

There is a substantial body of evidence suggesting that decreased accumbal cAMP signaling enhances reward value. For example, decreasing the activity of this cAMP system increases the reward value of cocaine (as evidenced by increased interresponse intervals during cocaine self-administration and decreased dose necessary to produce a conditioned place preference) whereas increasing the activity of the system decreases cocaine reward (Self et al., 1994, 1998; Lynch and Taylor, 2005). Moreover, reduced cAMP signaling within the NAcc promotes reinstatement of cocaine seeking (Self and Nestler, 1998), and conversely, increasing activity of this system prevents cocaine- 
Table 2. Behavior during the blockade of partner preferences

\begin{tabular}{lccrcc}
\hline & CSF & PTX & CTX & \multicolumn{1}{c}{ Sp shell } & Rp shell \\
\hline 24 h with mating & & & & & \\
$\quad$ Mating bouts $(n)$ & $28.2 \pm 8.7^{*}$ & $16.5 \pm 5.3$ & $14.6 \pm 5.5$ & $19.0 \pm 6.2$ & $20.9 \pm 4.1$ \\
$\quad$ Contact duration $(\min )$ & $801.1 \pm 65.5$ & $603.7 \pm 129.0$ & $831.5 \pm 42.8$ & $808.0 \pm 60.2$ & $838.3 \pm 13.7$ \\
$\quad$ Contact frequency $(n)$ & $64.5 \pm 11.1^{\mathrm{a}, \mathrm{b} * *}$ & $76.0 \pm 6.4^{\mathrm{a}}$ & $50.4 \pm 4.6^{\mathrm{b}}$ & $73.4 \pm 5.4^{\mathrm{a}}$ & $71.5 \pm 9.1^{\mathrm{a}, \mathrm{b}}$ \\
Partner preference test & $125.6 \pm 26.5$ & $144.8 \pm 19.5$ & $103.6 \pm 16.6$ & $106.3 \pm 18.9$ & $144.7 \pm 50.9$ \\
$\quad$ Cage entries $(n)$ & & & & &
\end{tabular}

*Mean \pm SEM. ${ }^{* *}$ Alphabetic letters indicate group differences $(p<0.05)$ shown by a SNK post hoc test following a one-way ANOVA. mediation of pair bond formation (Aragona et al., 2006) and $\mathrm{D}_{1}$-specific mediation of pair bond maintenance (Aragona et al., 2006) are likely regulated by the concentration of DA released and its corresponding receptor-specific activation within the NAcc. However, studies of real-time fluctuations in DA concentration (Venton and Wightman, 2003) in prairie voles are needed.

Importantly, opposing signaling by the DA receptor-cAMP system is consistent

induced reinstatement of drug seeking (Self and Nestler, 1998) (findings that are in general agreement with manipulations of DA receptors (Self et al., 1996; Khroyan et al., 2000) (but see Bachtell et al., 2005).

Furthermore, investigations of a down stream target in the cAMP signaling cascade, the transcription factor cAMP response element binding protein (CREB) (Carlezon et al., 2005), are consistent with decreased activity of the cAMP system mediating reward processing. Specifically, decreased CREB phosphorylation in the NAcc enhances cocaine reward and increased levels of phosphorylated CREB results in cocaine taking on aversive properties (Carlezon et al., 1998; Pliakas et al., 2001). Importantly, this effect was observed in the NAcc shell, but not the core (Carlezon et al., 1998).

It should be noted that the nature of opposing behavioral regulation by cAMP signaling within the NAcc is controversial because different conclusions have been reached based on studies using different behavioral paradigms. The negative relationship between cAMP signaling and drug seeking may be specifically related to primary reward and not other aspects of the behavior, such as general motivation (Lynch and Taylor, 2005). Increasing activity of the cAMP system, within the NAcc core, resulted in increased responding on a progressive ratio schedule for cocaine reinforcement (Lynch and Taylor, 2005). This demonstrates a positive relationship between cAMP signaling and motivation to acquire drug. Further, a positive relationship has generally been found between cAMP signaling and food seeking (Beninger and Gerdjikov, 2004). For example, cAMP signaling in the NAcc core is important for the acquisition of food seeking (Baldwin et al., 2002). Thus, cAMP signaling within the NAcc mediates multiple aspects of goal-directed behavior.

Data from the present study provide an interesting contribution to the debate regarding the role of accumbal cAMP signaling in motivated behavior because pair bonding is a naturally occurring learned association and thus an ethologically sound model for the neurobiology of motivation. Similar to studies addressing the reward value of cocaine (Self et al., 1998), pair bond formation is facilitated by decreased activity of the cAMP system, whereas increased activity of this system prevents this behavior. Because $\mathrm{D}_{2}$-like activation decreases cAMP activity (Missale et al., 1998) and facilitates pair bond formation (Aragona et al., 2006), the current evidence suggests that the decrease in cAMP signaling during pair bond formation is mediated by activation of $\mathrm{D}_{2}$-like $\mathrm{DA}$ receptors. However, we cannot exclude a possibility that other neurotransmitters that decrease cAMP signaling in NAcc could also be involved, which needs to be addressed in further experiments.

We have shown previously that mating results in a modest increase in DA transmission within the NAcc of male prairie voles (Aragona et al., 2003). Moderate elevations in extracellular DA will selectively activate high affinity $\mathrm{D}_{2}$-like dopamine receptors (Richfield et al., 1989). Conversely, low affinity $\mathrm{D}_{1}$-like receptors (Richfield et al., 1989) are activated by brief, high concentration, surges in DA concentration (Cheer et al., 2007). Therefore, the $\mathrm{D}_{2}$-specific with the anatomy of the NAcc. $\mathrm{D}_{1}$ - and $\mathrm{D}_{2}$-like receptors are largely expressed on separate projection neurons (Gerfen et al., 1990 ) and $D_{2}$-expressing neurons project selectively within the "indirect pathway" to the ventral pallidum (Lu et al., 1998; Kelley et al., 2005). This is especially interesting given that the ventral pallidum is essential for pair bonding in male prairie voles (Lim et al., 2004). Conversely, $D_{1}$-expressing neurons project in both the indirect (via the ventral pallidum) and direct pathways (Lu et al., 1998). However, these neurons are not activated during pair bond formation (Aragona et al., 2006).

The present study shows that decreased cAMP signaling specifically within the NAcc shell, but not the core, facilitates pair bond formation. Pair bonding is an associative process and, although highly interconnected, the NAcc shell and core mediate distinct aspects of associative learning (van Dongen et al., 2005). The NAcc shell is strongly implicated in unconditioned aspects of motivated behavior through processing information related to primary reward (Di Chiara et al., 2004; Wise, 2004). The NAcc core appears to be more important for conditioned aspects of motivated behavior (Kelley, 2004). Although pair bonding certainly involves processing of both unconditioned and conditioned information, the shellspecific nature from the present and previous studies (Aragona et al., 2006) suggests that $D_{2}$-like receptor mediated decreases in cAMP signaling may process unconditioned, reward-related, information necessary for pair bond formation. This is consistent with negative relationship between accumbal cAMP signaling and primary reward discussed above and with the fact that mating (Gingrich et al., 2000; Aragona et al., 2003), a primary reward (Everitt, 1990), facilitates pair bonding (Williams et al., 1992; Winslow et al., 1993). Therefore, like parent-offspring bonds (Champagne et al., 2004; Numan et al., 2005), monogamous pair bonding is a social attachment involving significant unconditioned processes mediated within the NAcc shell.

Finally, the present study focused on the canonical effector pathway downstream from DA receptors (Missale et al., 1998; Greengard, 2001; Neve et al., 2004). However, appreciation for independent pathways continues to grow (Gainetdinov et al., 2004). These systems, as well as other intracellular signaling systems involved in motivated behavior (Thomas and Everitt, 2001), must be examined before a comprehensive understanding of the intracellular regulation of pair bond formation is reached.

\section{References}

Aragona BJ, Liu Y, Curtis JT, Stephan FK, Wang ZX (2003) A critical role for nucleus accumbens dopamine in partner-preference formation in male prairie voles. J Neurosci 23:3483-3490.

Aragona BJ, Liu Y, Yu YJ, Curtis JT, Detwiler JM, Insel TR, Wang ZX (2006) Nucleus accumbens dopamine differentially mediates the formation and maintenance of monogamous pair bonds. Nat Neurosci 9:133-139.

Bachtell RK, Whisler K, Karanian D, SelfDW (2005) Effects of intra-nucleus accumbens shell administration of dopamine agonists and antagonists on cocaine-taking and cocaine-seeking behaviors in the rat. Psychopharmacology (Berl) 183:41-53.

Baldwin AE, Sadeghian K, Holahan MR, Kelley AE (2002) Appetitive instru- 
mental learning is impaired by inhibition of cAMP-dependent protein kinase within the nucleus accumbens. Neurobiol Learn Mem 77:44-62.

Beninger RJ, Gerdjikov T (2004) The role of signaling molecules in rewardrelated incentive learning. Neurotox Res 6:91-104.

Carlezon Jr WA, Duman RS, Nestler EJ (2005) The many faces of CREB. Trends Neurosci 28:436-445.

Carlezon Jr WA, Thome J, Olson VG, Lane-Ladd SB, Brodkin ES, Hiroi N, Duman RS, Neve RL, Nestler EJ (1998) Regulation of cocaine reward by CREB. Science 282:2272-2275.

Carter CS, Getz LL (1993) Monogamy and the prairie vole. Sci Am 268:100-106.

Champagne FA, Chretien P, Stevenson CW, Zhang TY, Gratton A, Meaney MJ (2004) Variations in nucleus accumbens dopamine associated with individual differences in maternal behavior in the rat. J Neurosci 24:4113-4123.

Cheer JF, Aragona BJ, Heien ML, Seipel AT, Carelli RM, Wightman RM (2007) Coordinated accumbal dopamine release and neural activity drive goal-directed behavior. Neuron 54:237-244.

Dewsbury DA (1987) The comparative psychology of monogamy. Nebr Symp Motiv 35:1-50.

Di Chiara G, Bassareo V, Fenu S, De Luca MA, Spina L, Cadoni C, Acquas E, Carboni E, Valentini V, Lecca D (2004) Dopamine and drug addiction: the nucleus accumbens shell connection. Neuropharmacology 47 [Suppl 1]:227-241.

Everitt BJ (1990) Sexual motivation: a neural and behavioural analysis of the mechanisms underlying appetitive and copulatory responses of male rats. Neurosci Biobehav Rev 14:217-232.

Everitt BJ, Robbins TW (2005) Neural systems of reinforcement for drug addiction: from actions to habits to compulsion. Nat Neurosci 8:1481-1489.

Eyny YS, Horvitz JC (2003) Opposing roles of D1 and D2 receptors in appetitive conditioning. J Neurosci 23:1584-1587.

Gainetdinov RR, Premont RT, Bohn LM, Lefkowitz RJ, Caron MG (2004) Desensitization of $\mathrm{G}$ protein-coupled receptors and neuronal functions. Annu Rev Neurosci 27:107-144.

Gerfen CR, Engber TM, Mahan LC, Susel Z, Chase TN, Monsma Jr FJ, Sibley DR (1990) D1 and D2 dopamine receptor-regulated gene expression of striatonigral and striatopallidal neurons. Science 250:1429-1432.

Gingrich B, Liu Y, Cascio C, Wang Z, Insel TR (2000) Dopamine D2 receptors in the nucleus accumbens are important for social attachment in female prairie voles (Microtus ochrogaster). Behav Neurosci 114:173-183.

Greengard P (2001) The neurobiology of dopamine signaling. Biosci Rep 21:247-269.

Ikemoto S, Glazier BS, Murphy JM, McBride WJ (1997) Role of dopamine D1 and D2 receptors in the nucleus accumbens in mediating reward. J Neurosci 17:8580-8587.

Insel TR (2003) Is social attachment an addictive disorder? Physiol Behav 79:351-357.

Keer SE, Stern JM (1999) Dopamine receptor blockade in the nucleus accumbens inhibits maternal retrieval and licking, but enhances nursing behavior in lactating rats. Physiol Behav 67:659-669.

Kelley AE (2004) Memory and addiction: shared neural circuitry and molecular mechanisms. Neuron 44:161-179.

Kelley AE, Baldo BA, Pratt WE, Will MJ (2005) Corticostriatalhypothalamic circuitry and food motivation: integration of energy, action and reward. Physiol Behav 86:773-795.

Khroyan TV, Barrett-Larimore RL, Rowlett JK, Spealman RD (2000) Dopamine D1- and D2-like receptor mechanisms in relapse to cocaine-seeking behavior: effects of selective antagonists and agonists. J Pharmacol Exp Ther 294:680-687.

Lim MM, Wang ZX, Olazabal DE, Ren X, Terwilliger EF, Young LJ (2004) Enhanced partner preference in a promiscuous species by manipulating the expression of a single gene. Nature 429:754-757.

Liu Y, Wang ZX (2003) Nucleus accumbens oxytocin and dopamine interact to regulate pair bond formation in female prairie voles. Neuroscience 121:537-544.

Lu XY, Ghasemzadeh MB, Kalivas PW (1998) Expression of D1 receptor, $\mathrm{D} 2$ receptor, substance $\mathrm{P}$ and enkephalin messenger RNAs in the neurons projecting from the nucleus accumbens. Neuroscience 82:767-780.
Lynch WJ, Taylor JR (2005) Persistent changes in motivation to selfadminister cocaine following modulation of cAMP-dependent protein kinase A (PKA) activity in the nucleus accumbens. Eur J Neurosci 22:1214-1220.

Missale C, Nash SR, Robinson SW, Jaber M, Caron MG (1998) Dopamine receptors: from structure to function. Physiol Rev 78:189-225.

Nestler EJ (2005) Is there a common molecular pathway for addiction? Nat Neurosci 8:1445-1449.

Neve KA, Seamans JK, Trantham-Davidson H (2004) Dopamine receptor signaling. J Recept Signal Transduct Res 24:165-205.

Numan M, Numan MJ, Pliakou N, Stolzenberg DS, Mullins OJ, Murphy JM, Smith CD (2005) The effects of D1 or D2 dopamine receptor antagonism in the medial preoptic area, ventral pallidum, or nucleus accumbens on the maternal retrieval response and other aspects of maternal behavior in rats. Behav Neurosci 119:1588-1604.

Pliakas AM, Carlson RR, Neve RL, Konradi C, Nestler EJ, Carlezon Jr WA (2001) Altered responsiveness to cocaine and increased immobility in the forced swim test associated with elevated cAMP response elementbinding protein expression in nucleus accumbens. J Neurosci 21:7397-7403.

Richfield EK, Penney JB, Young AB (1989) Anatomical and affinity state comparisons between dopamine D1 and D2 receptors in the rat central nervous system. Neuroscience 30:767-777.

Schwede F, Maronde E, Genieser H, Jastorff B (2000) Cyclic nucleotide analogs as biochemical tools and prospective drugs. Pharmacol Ther 87:199-226.

Self DW, Nestler EJ (1998) Relapse to drug-seeking: neural and molecular mechanisms. Drug Alcohol Depend 51:49-60.

Self DW, Terwilliger RZ, Nestler EJ, Stein L (1994) Inactivation of Gi and $\mathrm{G}(\mathrm{o})$ proteins in nucleus accumbens reduces both cocaine and heroin reinforcement. J Neurosci 14:6239-6247.

Self DW, Barnhart WJ, Lehman DA, Nestler EJ (1996) Opposite modulation of cocaine-seeking behavior by D1- and D2-like dopamine receptor agonists. Science 271:1586-1589.

Self DW, Genova LM, Hope BT, Barnhart WJ, Spencer JJ, Nestler EJ (1998) Involvement of cAMP-dependent protein kinase in the nucleus accumbens in cocaine self-administration and relapse of cocaine-seeking behavior. J Neurosci 18:1848-1859.

Stern JM, Lonstein JS (2001) Neural mediation of nursing and related maternal behaviors. Prog Brain Res 133:263-278.

Thomas KL, Everitt BJ (2001) Limbic-cortical-ventral striatal activation during retrieval of a discrete cocaine-associated stimulus: a cellular imaging study with gamma protein kinase C expression. J Neurosci 21:2526-2535

van Dongen YC, Deniau JM, Pennartz CM, Galis-de Graaf Y, Voorn P, Thierry AM, Groenewegen HJ (2005) Anatomical evidence for direct connections between the shell and core subregions of the rat nucleus accumbens. Neuroscience 136:1049-1071.

Venton BJ, Wightman RM (2003) Psychoanalytical electrochemistry: dopamine and behavior. Anal Chem 75:414A-421A.

Wang ZX, Aragona BJ (2004) Neurochemical regulation of pair bonding in male prairie voles. Physiol Behav 83:319-328.

Wang ZX, Yu G, Cascio C, Liu Y, Gingrich B, Insel TR (1999) Dopamine D2 receptor-mediated regulation of partner preferences in female prairie voles (Microtus ochrogaster): a mechanism for pair bonding? Behav Neurosci 113:602-611.

Williams JR, Catania KC, Carter CS (1992) Development of partner preferences in female prairie voles (Microtus ochrogaster): the role of social and sexual experience. Horm Behav 26:339-349.

Winslow JT, Hastings N, Carter CS, Harbaugh CR, Insel TR (1993) A role for central vasopressin in pair bonding in monogamous prairie voles. Nature 365:545-548.

Wise RA (2004) Dopamine, learning and motivation. Nat Rev Neurosci 5:483-494.

Yip KP (2006) Epac-mediated $\mathrm{Ca}^{2+}$ mobilization and exocytosis in inner medullary collecting duct. Am J Physiol Renal Physiol 291:F882-890.

Young LJ, Wang ZX (2004) The neurobiology of pair bonding. Nat Neurosci 7:1048-1054 